\title{
«Episodio de las hebritas de oro». Hilos entre el romance y el relato
}

\section{«Episodio de las hebritas de oro». Links between the Singing Game and the Story}

\section{Noé Blancas Blancas}

Universidad Popular Autónoma del Estado de Puebla MÉXICO

noe.blancas@upaep.mx

[Hipogrifo, (issn: 2328-1308), 6.1, 2018, pp. 503-522]

Recibido: 24-07-2017 / Aceptado: 09-10-2017

DOI: http://dx.doi.org/10.13035/H.2018.06.01.35

Resumen. En este trabajo analizo las correspondencias actanciales, narrativas y estilísticas entre la ronda infantil «Hilitos de oro» y el cuento «Episodio de las hebritas de oro», de Agustín Yáñez. El acercamiento a los recursos narrativos de la ronda -comienzo in medias res, propensión al diálogo-, y a ciertos rasgos estilísticos como la repetición, nos permiten observar, por un lado, que estos mismos recursos se replican en el relato; y por otro lado, que contribuyen a una actualización o presentificación de las historias que narran. Asimismo, se descubre la huella, en el relato moderno, de la oralidad, la narratividad y el manejo del tiempo que provienen del antiguo romance español. De manera que, si la esencia de la ronda es la representación, al determinar la estructura y la narración del cuento, este llega a constituir también una performance.

Palabras clave. Romance; ronda infantil; Hilitos de oro; Agustín Yáñez; Flor de juegos antiguos.

Abstract. In this paper we analyze the actantial, narrative and stylistic correspondences between the childhood «Hilitos de oro» and the short story «Episode of the golden hebritas», by Agustín Yáñez. The approach to the narrative resources of the round -starting in medias res, propensity to dialogue-, and to certain stylistic features such as repetition, allow us to observe, on the one hand, that these same resources are replicated in the story; and on the other hand, that to provide an actualization or presentification of the stories they tell. Likewise, the trace, in the modern story, of orality, narrativity and time management that comes from ancient romance 
is discovered. So, if the essence of the round is representation, when determining the structure and storytelling of the story, this also constitutes a performance.

Keywords. Romance; ronda [singing game]; «Hilitos de oro»; Agustín Yáñez; Flor de juegos antiguos.

\section{EL ROMANCE}

El romance «Hilitos de oro», motivo principal del cuento «Episodio de la hebritas de oro», de Agustín Yáñez ${ }^{1}$, determina la historia y ciertos recursos narrativos y estilísticos del relato, que en conjunto contribuyen a una presentificación de la narración, rasgo esencial de la ronda infantil. Un análisis comparativo de tales recursos en una y otra obra nos permite leer el relato como una representación narrativa. Así, voy a referirme primero al romance en concreto para después observar su relación con el cuento.

Aunque en «Episodio de la hebritas de oro» no se menciona cómo se juega la ronda, podría ser de alguna de las maneras que Pedro Henríquez Ureña registró en Durango y en la ciudad de México. En Durango:

Los niños se ponen en rueda. El caballero viene saltando en un solo pie y entra en la rueda. Después se va, y vuelve cuando se le llama: Vuelva, vuelva. Escoge finalmente a una niña; y después vuelve a comenzar el juego con otra, hasta que se lleva a todas las niñas. Los versos se recitan, no se cantan?

En la ciudad de México, la escritora Laura Méndez de Cuenca le explicó a Henríquez Ureña que, después de que el caballero escogía a la niña y volvía por la «dama» para llevársela,

encontraba que el grupo se había convertido en otra cosa, generalmente una tienda de cintas y listones, y cada niña era un listón de determinado color, para la venta. El caballero no venía saltando sobre un solo pie, como en el juego de hoy, sino a caballo en un palo ${ }^{3}$.

1. Yáñez, 1967, pp. 57-60. En adelante, para evitar la profusión de citas, cuando se trata de este libro, anoto a renglón seguido y entre paréntesis, el número de página.

Ya desde el título en que aparece el relato en cuestión, Flor de juegos antiguos, Yáñez alude al romancero: «Flor»: antiguamente, conjunto de cantares, romances, poemas o dichos de un pueblo, una época o un tema. Son de sobra conocidos títulos como: Flor de romances, Floresta de poesía, Florilegio, e incluso nuestros tradicionales «Juegos florales»; en todos estos casos, se mantiene ese sentido.

2. Henríquez Ureña y Wolfe, 2008, p. 35.

3. Henríquez Ureña, y Wolfe, 2008, p. 36. Al parecer, en España se juega de otras varias maneras. Francisco Rodríguez Marín lo explica así: «Colócanse varias niñas e hilera, sentadas en el suelo, cada una entre las piernas de la anterior, a la que vuelve, naturalmente, la espalda; la última de la fila hace el papel de madre, y las demás... son sus hijas. Así colocadas, llega un niño o niña, que hace de embajador, entre la cual y la madre se entabla en diálogo» (Rodríguez Marín, 1931, p. 672). Por su parte, Tomás Lozano afirma: «En algunas zonas de España el juego consiste en que dos niñas se colocan una frente a la otra agarrándose las manos y levantando los brazos en alto, formando un arco. Los/as demás participantes forman una fila y van y vienen pasando por debajo del arco [...]. / En otros casos el juego se escenifica. El 
Este romance es uno de los dos mil, según la percepción de Aurelio González ${ }^{4}$, que desde el siglo XIX se han recogido en América, y que se conservan en México en forma de rondas infantiles. Proveniente de los antiguos cantares medievales, de los cuales el más antiguo que poseemos es quizá el que recoge Lucas de Túy en $1236^{5}$, el romance español comenzó muy pronto a ser material de la literatura, como el cantar lo fue para la poesía cortesana hasta $1580^{6}$.

Mercedes Díaz Roig considera el romance la «expresión española de la balada», aunque uno y otra son claramente diferenciables ${ }^{7}$. Por su parte, defienden el origen épico del romance -contra la teoría de un origen lírico-Milá y Fontanals ${ }^{8}$, Andrés Bello, Menéndez Pelayo y Menéndez Pidal, quien asegura que «el romance se origina a partir de la canción de gesta, por sucesivos desgajamientos de aque\|los trozos que más gustaban al público y que éste hacía repetir al juglar», aunque «los romances más antiguamente documentados son novelescos líricos»9. Según A. D. Deyermond, hacia 1400 el romance gana «el favor popular frente a la épica» ${ }^{10}$; el más antiguo, que con seguridad se desprende de un hecho histórico, es el que contiene «el desafío del rey por parte del Prior de San Juan», suceso fechado en 1328, aunque los romances que no surgen de un suceso histórico son incluso más antiguos ${ }^{11}$.

Impresos, aparecen primero en cuadernillos de 8, 16 o 32 páginas; el más antiguo parece haberse editado en Zaragoza hacia 150612, aunque hay copias escritas anteriores a esta fecha, como el Gentil dona, gentil dona..., «copiado hacia 1421»»3.

rey manda un caballero que hace de mensajero y se entrevista con la madre de las bellas damas mientras la escenificación se acompaña del verso» (Lozano, 2007, p. 573). El propio Henríquez Ureña registra otra manera de jugarse, en Santo Domingo: «Los niños se sientan en fila, poniendo en la cabecera a la niña de más edad como reina, y ordenándose los demás de mayor a menor, para representar la familia real; sólo dos niños no se sientan: uno es caballero y otro su criado». La ronda se canta por turnos y al final, elegida la novia, el «pequeño drama» puede concluir con las recomendaciones de la reina para el cuidado de su hija o bien, se prolonga según la inventiva de los niños. Según este desenlace, detrás del diálogo inicial no hubo sino traición: la familia del rey moro nunca tuvo intención de entregar a la hija. Cuando el caballero envía su criado a buscarla, con esta frase: «Que le manden la niña», se le contesta con evasivas, de las cuales se ha hecho clásica la primera: «Que se está peinando»; y las enumeración de causas dilatorias puede hacerse interminable. Cuando se han agotado las prendas del vestido y de adorno, se recurre a la mentira: «Que se cayó en un pozo», con lo cual suele terminar todo, y la familia ataca al caballero (Henríquez Ureña, 2008, pp. 63-64).

4. González, 2016.

5. «En Cañatañacor / Almancor perdió ell atamor» es un cantar que surge a la muerte de Almanzor en 1002. Ver Frenk, 1984, pp. 13-14.

6. «... el popularismo, en realidad, no fue sino la infiltración de elementos nuevos dentro del marco mismo de la poesía cortesana» (Frenk, 1984, p. 21).

7. Díaz Roig, 1987, p. 13.

8. Ver Milá y Fontanals, 1959

9. Ver Menéndez Pidal, 1953. Tomado de Díaz Roig, 1987, p. 21.

10. Deyermond, 2001, p. 220.

11. Deyermond, 2001, p. 224.

12. Díaz Roig, 1987, p. 14

13. Díaz Roig, 1987, pp. 14 y 16, nota 5. 
Luis Milán recopila, en 1536, las melodías de varios romances y cantarcillos en su Libro de vihuela; en 1556 aparece el Cancionero de Upsala; en 1561, en Valencia, el Sarao de amor recopilado por Juan Timoneda; y en 1562, en Barcelona, la Flor de enamorados. Con Sebastián de Horozco y Cristóbal Castillejo, la canción popular se vuelve material de la poesía culta ${ }^{14}$. Juan de Mal Lara, en 1568, hace anotaciones y adiciones a varios cantares recopilados por Hernán Núñez, en La filosofía vulgar; y Rodrigo Caro estudia los juegos infantiles y recoge rimas y coplillas ${ }^{15}$.

En cuanto al estudio moderno del romance español, éste podría fecharse en 1916, cuando Pedro Henríquez Ureña comienza a escribir La versificación irregular en la poesía castellana - publicado al año siguiente-, y Ramón Menéndez Pidal pronuncia su conferencia «La primitiva poesía lírica española». Entre 1935 y 1969, Dámaso Alonso, Daniel Devoto, Aurelio Roncaglia, Santiago Magariños, José Manuel Blecua, José Maria Alín, Antonio Sánchez Romeralo, entre otros, han hecho contribuciones invaluables ${ }^{16}$.

En el caso concreto de «Hilitos de oro», que Agustín Yáñez incorpora en su relato ${ }^{17}$, aunque no es sencillo establecer la fecha de su origen, es válido aceptar, con Margit Frenk ${ }^{18}$, que proviene del siglo XVI. Contribuye a esta postura la información que proporciona Ramón Menéndez Pidal en Los romances de América y otros estudios $^{19}$. En este libro, Menéndez Pidal recoge una versión procedente del romancero judío de Tánger:

14. Frenk, 1984, pp. 36-37

15. Frenk, 1984, p. 45.

16. Frenk, 1984, pp. 55-56.

17. Anoto aquí la versión que aparece en el cuento de Yáñez: Hebritas, hebritas de oro,

se me viene quebrando un pie,

que en el camino me han dicho,

lindas hijas tiene el rey.

Téngalas o no las tenga

nada le importa a usted.

Ya me voy muy enojado

de los palacios del rey,

que las hijas del rey moro

no me las dan por mujer.

Vuelva, vuelva, caballero,

no sea tan descortés,

y de las hijas que tengo

escoja la más mujer.

Esta escojo por mi esposa,

y por mi mujer también,

que parece una rosita

acabada de nacer (pp. 58-59).

18. Ver Frenk, 1973.

19. Menéndez Pidal, 1941 
130.- Buscando novia.

(Tánger.)

De Francia vengo, señora, de un pulido mercader;

en el camino me han dicho que bellas hijas tenéis...

La cantan al corro las niñas de Tánger, como las de España y América ${ }^{20}$.

La presencia de este romance entre los judíos de Tánger nos lleva a asumir que lo aprendieron antes de su expulsión de España, en 1492, y que lo han conservado en la memoria hasta el siglo XX, cuando lo recoge Menéndez Pidal. Sin embargo, también pudieron haberlo aprendido posteriormente. Como bien advierte Menéndez Pelayo, a la emigración española se sumó en los siglos XVI y XVII la portuguesa: «Estos nuevos desterrados, entre los cuales no faltaban cultivadores de la poesía artística, pudieron renovar el fondo de la poesía tradicional, importando nuevos romances» ${ }^{21}$. Además, éstas no fueron las únicas migraciones. Hay que mencionar, siguiendo a Menéndez Pidal, que los exiliados lograron burlar durante siete años la Pragmática de expulsión del 31 de marzo de 1492 -lo que ocasionó la segunda Pragmática, de 1499, mucho más radical-, con lo cual la circulación de romances españoles pudo haber continuado. El contacto se mantuvo, por otra parte, gracias a la estancia de los exiliados en los presidios españoles del norte de África en 1587 y 1601, y en Castilla -sobre todo, portugueses - durante el reinado de Felipe III, muerto en $1621^{22}$.

La tradición del romance en Tánger también pudo verse renovada con la repetida impresión del Cancionero de Romances en Amberes a partir de 1550. Por cuanto a Tánger, la comunicación con España debió ser aún mayor. De manera que, concluye Menéndez Pidal: «La tradición judía [...] no es una prueba de que el romance en ella conservado sea anterior al siglo XVI, sino sólo una presunción. La mayoría de los romances judíos son medioevales; pero no todos» ${ }^{23}$. Efectivamente, que «Hilitos de oro» date del siglo XV es sólo una «presunción». Sin embargo, es posible datarlo, si no en el siglo XV, al menos antes del XVII -como vimos, Margit Frenk lo fecha en el XVI-, considerando que fue usado por Lope de Vega. Así lo expone Menéndez Pidal en su ya citado libro:

Es un romance de los que cantan las niñas jugando al corro, lo mismo en Madrid que en otras partes. No está incluido en los romanceros. Su antigüedad, no obstante, es grande; ya en tiempos de Lope de Vega, en el entremés de Daca mi

20. Menéndez Pidal, 1941, p. 195.

21. Menéndez Pelayo, Antología de poetas líricos castellanos, tomo X, p. 296; cito de Menéndez Pidal, 1941, p. 137.

22. Menéndez Pidal, 1941, p. 138.

23. Menéndez Pidal, 1941, p. 143. 
mujer, un sacristán al padre de su novia que le niega el casamiento, le dice, recordando este romance:

Pues me niegas la suegrez,
enojado me voy, enojado $\quad$ a los palacios del Rey... ${ }^{24}$.

Por su parte, en su libro Cantemos al alba, Tomás Lozano afirma: «Este juego está documentado desde el siglo XVI en España y se encuentra muy difundido por América Latina donde se han recogido muchísimas versiones en dieciséis países» ${ }^{25}$.

Hoy día, ya bien entrado el siglo XXI, en América, «Hilitos de oro» muestra una vitalidad incuestionable ${ }^{26}$. Margit Frenk, en su monumental Nuevo corpus de la antigua lírica popular hispánica, afirma que existen

abundantes versiones modernas, de Andalucía, Asturias, y Cataluña, y referencias a otras, portuguesas y americanas; T. Brandao, «La condessa», RDTP, 10 (1954), pp. 591-643, aduce versiones de España, Portugal, Brasil, Argentina, México y Nicaragua, y remite a correspondencias italianas, francesas e inglesas ${ }^{27}$.

En México concretamente existe una infinidad de versiones, algunas de las cuales muestran cierta «influencia local», según lo registra Mercedes Díaz Roig, e incorporan términos como pinacate y mayate, que aluden a insectos ${ }^{28}$; incluso alguna versión nombra a Pancho Villa, «mención desgajada de todo contexto histórico, pero que refleja la popularidad del Caudillo del Norte» ${ }^{29}$.

Esta influencia local tiene su contraparte, que es la descontextualización del romance original. La alusión al rey moro, por ejemplo, carece ya de todo sentido que, en su origen, pudo ser de enemistad, aunque Deyermond puntualiza:

A la caída de Granada en 1492, los moros dejaron de ser considerados como un peligro, aunque se deba señalar que siempre habían sido tratados con cierta simpatía por los autores de romances [...].

En la nueva situación son considerados indulgentemente en los romances moriscos, en que el personaje moro es visto como un amante noble aunque desdeñado ${ }^{30}$.

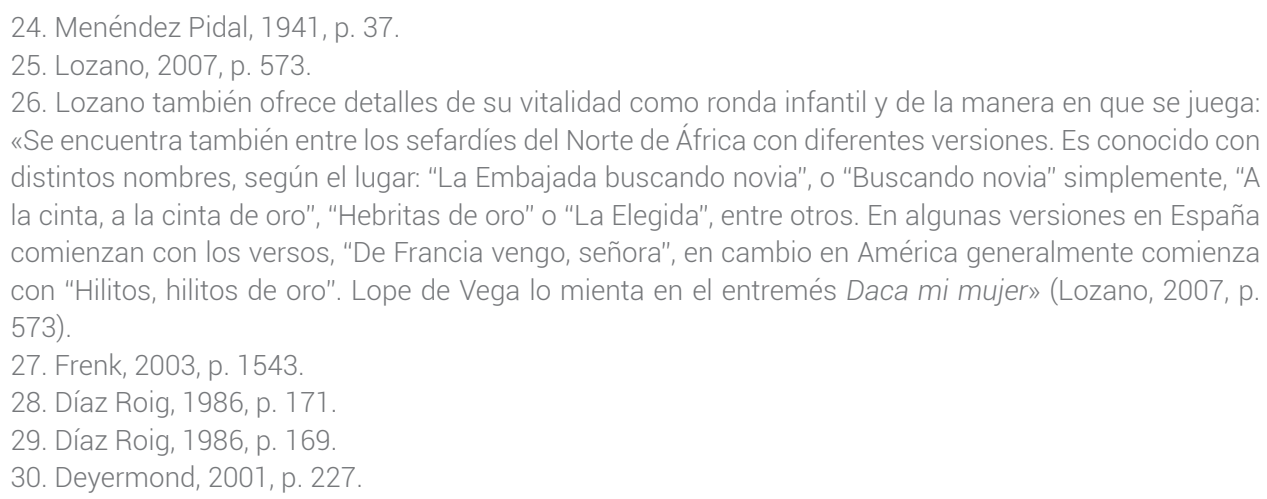


Así lo entiende también Díaz Roig:

Quizás para algunas personas moro conserve la connotación de enemigo o de malvado, pero en general puede decirse que se ha perdido en México la noción del significado, real o metafórico, de la palabra; el motivo no tiene, creo yo, un carácter histórico, sino que se inscribe en el mundo legendario y fantástico de lo desconocido ${ }^{31}$.

Efectivamente, para Gabriel, el protagonista del cuento de Yáñez, el rey moro de la ronda podría ser su tío Cipriano: «Mi tío, con su larga barba dorada, parece uno de los reyes magos» (p. 58). Rey moro / Rey de oriente obedecen al motivo que refiere Díaz Roig: «mundo legendario y fantástico de lo desconocido».

Observemos ahora algunas características del romance, comenzando por la métrica y la rima, como las más evidentes. Género poético, el romance está constituido por versos asonantados de dieciséis sílabas, que fácilmente pueden leerse como octosílabos ${ }^{32}$. Díaz Roig cree que el doble octosílabo debió provenir de la métrica épica de los siglos XII y XVIII, por lo cual seguimos escribiéndolo en versos largos monorrimados, considerando los cortos como hemistiquios ${ }^{33}$. En ese sentido, Díaz Roig estima que el estrofismo es ajeno al romance, pues parece más bien «una invención de los músicos del siglo XVI que querían adaptar la letra a la música con que se cantaban los textos» ${ }^{34}$, por lo cual, más que el estrofismo, lo propio del romance es la tirada.

«Hilitos de oro» está constituido por versos que podrían ser de dieciséis sílabas monorrimados o de ocho con rimas pares asonantadas; en las distintas recopilaciones aparece de ambos modos, aunque predomina el corte octosilábico. Sin embargo, por su antigüedad y porque todo el romance mantiene la rima en e, podríamos admitir que su forma original fue el hexadecasílabo dividido en hemistiquios octosílabos.

En cuanto al estilo, Díaz Roig identifica como principales recursos formales la repetición, la antítesis y la enumeración, en lo que coincide con Deyermond, quien observa, a su vez, un frecuente «uso del lenguaje formular, que suscita la cuestión de composición oral» y el «recurso lírico de la repetición» 35 .

Precisamente, entre los elementos del «estilo básico» del romancero y de la lírica popular relacionados con la facilidad para su memorización, Díaz Roig identifica la repetición de tipo reiteración ${ }^{36}$. Este recurso es evidente en la apertura de «Hilitos de oro», sin importar la versión de que se trate ${ }^{37}$ : motivos semejantes con repetición

31. Díaz Roig, 1986, p. 169

32. Deyermond, 2001, p. 225.

33. Díaz Roig, 1987, p. 21

34. Díaz Roig, 1987, p. 22.

35. Deyermond, 2001, p. 230

36. Díaz Roig, 1987, p. 45.

37. En su libro Estudios y notas sobre el Romancero, Díaz Roig lo identifica con la entrada «Hilitos de oro». Díaz Roig, 1986, p. 238. 
(«hilitos, hilitos de oro»); y sin repetición pero con enumeración dual («Ángel de oro, arenita de un marqués») ${ }^{38}$.

Consideremos ahora el asunto de la historia que cuenta «Hilitos de oro», pues a diferencia de la lírica infantil, que Ana Pelegrín denomina «juego-rima» o «retahíla» - para diferenciarla de las adivinanzas, canciones o romances-39, y que constituye un «decir poético» conformado por «palabras sin sentido, burlas, disparates» ${ }^{40}$, este romance cuenta una historia. El tema que trata, la «elección amorosa», es uno muy recurrente, como bien observa Pedro Cerrillo ${ }^{41}$ : un caballero pretende desposarse con una de las hijas del rey. En diálogo con la madre, expresa su interés por las muchachas; desdeñado primero, es aceptado luego gracias a su riqueza, y no sólo se le concede el matrimonio, sino además elegir a la «más mujer». Son pues la riqueza del caballero y la ambición de la madre los elementos que resuelven la trama.

Probablemente el recurso más determinante sea el uso del diálogo. De hecho, observa Díaz Roig, rara vez el romance se presenta como «pura narración en tercera persona». Más bien: «Suele tener una buena dosis de diálogo», lo cual podría ser resultado de su tradicionalización, de manera que hay romances totalmente dialogados ${ }^{42}$

Este es el caso de «Hilitos de oro». Uno de los efectos más evidentes quizá sea el hecho de que la historia comienza in medias res, rasgo que Deyermond ha observado ya como característica de los romances:

La mayoría de estas piezas comienzan in medias res, sin alusión a su contorno, y muchas de ellas concluyen antes de que la acción haya sido llevada a término. [...] cierran con un final enigmáticamente repentino -lo que Menéndez Pidal ha señalado certeramente como un «saber callar a tiempo» ${ }^{43}$.

Y muy probablemente este uso del diálogo haya contribuido a su conversión a la lírica infantil. En tanto ronda, principalmente, pero también gracias a su modo dialogado, constituye, como todo juego, esencialmente un drama. Como observa Pelegrín, en el juego-rima, la producción verbal «se presenta como condensación de actos expresivos diversos (lenguaje verbal, gestual y sonoro en el espacio y el tiempo), y tiene las características del "texto dramático"»44.

Así lo había observado ya Henríquez Ureña. Al explicar la manera en que se juega «Hilitos de oro»y detallar los movimientos que se van realizando, manifiesta

38. Díaz Roig, 1986, pp. 52-54.

39. Pelegrín, 2002, p. 17

40. Pelegrín, 2002, p. 11

41. Cerrillo, 2013, p. 401. El Archivo del Seminario Menéndez Pidal conserva una versión recogida en Alcolea del Río, Sevilla, en 1929, más extensa que la del cuento de Yáñez, con algunas variantes (el inicio es «De Francia vengo, señora», el caballero es francés y busca esposa para su hijo portugués; son tres las hijas que se ponen a elección, etc.) y con otros temas agregados, como las recomendaciones de la madre sobre el cuidado que deberán dispensar a la hija elegida. Ver Cerrillo, 2013, pp. 401-403.

42. Díaz Roig, 1987, p. 24.

43. Deyermond, 2001, pp. 230-231.

44. Pelegrín, 2002, p. ii. 
claramente el modo dialogado - «el niño contesta»- y le llama «pequeño drama» 45 . Y en el cuento de Yáñez, el propio narrador-protagonista, Gabriel, al imaginar que volverá a jugar la ronda con su prima, la imagina como un drama: «Y nada me importará que alguna muchachota fea del rancho, que figura la "madre" de las hijas, como aquí la sobrina del zapatero -tan gorda-, me grite: / Téngalas o no las tenga». Tras el rechazo de la madre: «Yo les enseñaré mi espejito francés o un pañuelo de seda, como aquí le he enseñado a la zapatera una de mis ágatas más bonitas [...]. Y por el interés del espejito, la "madre" me llamará». Una vez puesto a escoger: "Con qué gusto y prontitud me dirigiré a mi prima [...]. Ella entonces sonreirá [...]. Me tenderá las dos manos. Yo me estremeceré» (pp. 58-59).

Efectivamente, «Hilitos de oro», como toda ronda, más que un discurso, es una representación. No cuenta, sino representa. Los niños, al ejecutar el diálogo, escenifican y presentifican la historia; el diálogo hace que la historia ocurra en el momento en que se canta.

Por otra parte, la utilización del romance en la literatura, desde el siglo XVI, también está relacionada con su condición dramática, lo cual es evidente ya en el hecho de que fueron géneros dramáticos los primeros en incorporarlos.

Hacia 1580, el vulgo urbano reclama su poesía propia, que se nutre de la popular, inmolándola, y que se reúne, a partir de 1589, en tomitos llamados Flor de varios romances nuevos, que luego se recogen en el Romancero general de 1600, donde aparecen como anónimos, aunque sus autores son bastante conocidos: Lope de Vega, principalmente, pero también Góngora, Liñán de Riaza, Lasso de la Vega, Juan de Salinas, Quevedo, etc. ${ }^{46}$ Otros más, en el Siglo de Oro, los glosan, los usan para ambientar escenas de bodas, bautizos, vendimias, serenatas: «se nos presentan como un eco o un comentario, patético o burlesco, cuando no como un anticipo de los sucesos» ${ }^{47}$, advierte Margit Frenk. Y esto puede observarse claramente en Lope de Vega, como observa Casalduero:

[Lope] utiliza las canciones con un propósito escénico y dramático evidente; sin embargo, la función primordial consiste en trasladar la acción a un plano exclusivamente lírico, en el cual el tema se despoja de toda contaminación real, y al sublimarse cristaliza en su esencialidad ${ }^{48}$.

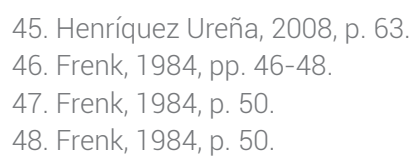

Sobre la manera en que el romance se incorpora en otras obras, Frenk abunda: «Un cantarcillo mínimo, cantado una sola vez, puede llenar toda una escena de misteriosa y escalofriante intensidad, proyectando su luz sobre la obra entera. Así ocurre en Los amantes de Teruel de Tirso, en el Caballero de Olmedo de Lope. La aparición de los cantores puede hacer cambiar de rumbo a la acción misma. Las alabanzas que tras las bambalinas cantan los músicos del príncipe a la hermosa labradora Pascuala, cuando va a cenar con su marido, provocan una impresionante escena de La luna de la sierra de Vélez de Guevara; en La ocasión perdida de Lope los cantos de los aldeanos hacen que don Juan pierda, precisamente, la ocasión» (Frenk, 1984, pp. 50-51). Para una revisión de la presencia del romance -y de los juegos 
Hay incluso comedias basadas en algún romance: La niña de Gómez Arias, de Vélez de Guevara; El caballero de Olmedo, de Lope, por ejemplo. Se usan también en rimas infantiles, como las del Baile curioso de Pedro de Brea; Sor Juana también los utiliza no escasamente ${ }^{49}$. La influencia del romance en la literatura continúa hasta el siglo XX y aún en el XXI. En México, encontramos huellas en gran número de poetas ${ }^{50}$. En la narrativa, el caso de Flor de juegos antiguos de Agustín Yáñez, que aquí nos ocupa, es excepcional por cuanto los relatos que incluye no sólo aluden o citan algunos romances vueltos rondas infantiles, sino que replican sus recursos narrativos y estilísticos.

Después de haber comentado la antigüedad, las características formales y la influencia del romance en la literatura desde el siglo XVII, veamos ahora la manera en que, concretamente, la ronda «Hilitos de oro» determina la historia, la estructura, e incluso ciertos rasgos estilísticos del «Episodio de las hebritas de oro».

\section{EL RELATO}

«Episodio de las hebritas de oro» cuenta una historia muy semejante a la del romance que cita. Gabriel se ha enamorado de su prima, «de trenzas de oro», durante el tiempo en que ella ha estado de visita por las celebraciones navideñas y con quien ha jugado principalmente a las rondas. Dado que la prima debe volver al rancho, el juego resulta, según advierte Richard A. Young en Agustín Yáñez y sus cuentos, «fuente de placer y de pena», pues la prima no le corresponde; es el vehículo con que los sentimientos se expresan y, al mismo tiempo, el que une las dos partes de la narración ${ }^{51}$.

Veamos un poco más de cerca las historias. Comencemos por la evidente relación entre el motivo de la ronda, los «hilitos» o «hebritas de oro» y la prima de Gabriel, descrita como «la de trenzas de oro»; y la aún más evidente identificación con la hija del rey moro que el «caballero» elige para su esposa: la elección de una y otra joven se funda en el mismo criterio, por ser la «más mujer». Gabriel explica esta condición diciendo que su prima, quien «no cumple todavía los quince años», «ya es una muchacha hecha y derecha» (p. 58) y «sabe hacer de comer, y barre y lava y cose» (p. 59).

infantiles - en la literatura, ver el capítulo «III. Los juegos en la literatura», del libro Cada cual atienda su juego: de tradición oral y literatura, de Ana Pelegrín (1984).

49. Frenk, 1984, pp. 51-53.

50. Menciono sólo dos ejemplos. El uso del romance en Muerte sin fin, es un tópico bastante trabajado; baste mencionar a Beatriz Garza Cuarón, quien advierte, en «Claridad y complejidad en Muerte sin fin de José Gorostiza», que la décima parte del poema es «un romance octosilábico, que imita la forma de un juego infantil» (Garza Cuarón, 1989, p. 1135). En cuanto a Alfonso Reyes, además de aprovechar los recursos del romance en su poesía, él mismo declaró su simpatía en varias ocasiones: «el romance viejo español es, en su género, una creación artística tan excelsa como los coros de la tragedia griega» (Reyes, 1960, p. 131)

51. Young, 1978, p. 116. 
Como vimos, en el romance, un caballero solicita la mano de una de las hijas del rey; tras una breve negativa, y luego de evidenciar su riqueza, se le concede escoger a la «más mujer». En el cuento de Yáñez, el niño narrador es despreciado, no por falta de riquezas, sino aparentemente porque resulta muy menor para la prima - la diferencia es de cinco años-, pero sobre todo, aunque no se menciona en el cuento, porque son parientes. Por lo demás, no es la madre quien se opone, sino la prima misma, quien está «encaprichada en el casorio» con un «empleado en rentas de Teocaltiche» (p. 59), no obstante que su padre, el tío Cipriano, se opone y, además, «le cumple todos sus antojos», por lo que ha resuelto «ponerla de interna y quiere que nadie sepa en dónde» (p. 59) -como accidentalmente escucha Gabriel comentar a sus padres.

Tenemos, entonces, que el personaje femenino central -podríamos decir, el objeto de deseo- es el mismo en uno y otro relato; mientras que el personaje masculino -el sujeto que desea- difiere al menos en este punto: en la ronda el caballero triunfa en su empresa pero el niño del cuento fracasa. Otros personajes también se corresponden: el tío Cipriano, «con su larga barba dorada, parece uno de los reyes magos», parece el «rey moro» de la ronda.

Pero la ronda no sólo determina las acciones del relato, sino también ciertos recursos narrativos. Como vimos, el romance, fiel a su género - según ha observado Deyermond ${ }^{52}-$, comienza in medias res y concluye de forma repentina. Esto mismo podemos decir del cuento de Yáñez: comienza no al principio de las acciones (un día mi prima vino a pasar la Navidad con mi familia), sino en el momento crítico, in medias res: «Ya pasó la Nochebuena [...] mi prima, que vino unos días de visita, se vuelve mañana al rancho» (p. 57). Asimismo, termina abruptamente: enterado del deseo de la prima por casarse, y de la determinación del tío Cipriano de «ponerla de interna», el niño sólo expresa: «Nunca voy a olvidarlo. Tengo mucho frío. Me duele la cabeza» (p. 60), sin que se resuelva la historia principal.

Quizá el recurso del antiguo romance vuelto ronda que cobra aquí mayor relevancia sea el uso del diálogo que se mantiene de principio a fin, con lo cual se produce una presentificación de la historia que se cuenta. Si bien el cuento no constituye un diálogo -insostenible en un relato literario-, varios aspectos narrativos se corresponden con el modo dramático.

En primer término, la historia se cuenta desde la autodiégesis, en una especie de soliloquio que determina, entre otras cosas, la persistencia del tiempo presente. Gabriel comienza lamentándose de que hayan concluido las fiestas: «Ya pasó la Nochebuena y pasó el Año Nuevo. Ya pasaron los Santos Reyes Magos» (p. 57). No se dice «Ya había pasado...», sino «Ya pasó», y este pretérito definido da cuenta de una deixis en presente: Nochebuena, Año Nuevo y Santos Reyes acaban de pasar. Y sigue: «Están quitando el Nacimiento» (p. 57). Como es fácil observar, la voz autodiegética no se ubica en la ulterioridad ${ }^{53}$, sino en el momento en el que se produ-

52. Deyermond, 2001, pp. 230-231

53. Para Reis y Lopes, la ulterioridad - esto es, la temporalidad posterior a todas las acciones narradas - es una característica de la narración extradiegética, por definición, aquella en que el narrador se 
cen las acciones: el «aquí y ahora» de las acciones coincide con el «aquí y ahora» del discurso.

La insistencia en el tiempo presente origina una repetición que resulta muy significativa por cuanto se corresponde con una de las características más estudiadas en el antiguo romance y también en la lírica infantil. Como he anotado, la repetición del tipo reiteración, considerada por Díaz Roig como uno de los elementos del «estilo básico» del romance ${ }^{54}$, aparece claramente en la apertura del romance: «Hilitos, hilitos de oro». Esta reiteración del inicio del romance se replica nítidamente en el inicio del cuento: «Ya pasó la Nochebuena y pasó el Año nuevo. Ya pasaron los Santos Reyes Magos» (p. 57). Y seguirá apareciendo: «Ya guardó mi mamá la capita de pastor [...] Ya guardó mi tía el pandero y las güijolas» (p. 57). «Mi prima, la de trenzas de oro [...] Mi prima, tan franca» (p. 57). Tenemos: ya pasó / y pasó / ya pasaron; ya guardó / ya guardó; mi prima / mi prima. Y también una repetición acumulativa: «lo más triste, lo más sordamente triste». En definitiva, no es una coincidencia; se trata de una reelaboración estilística que la ronda genera en el relato de Yáñez. Uno de los efectos más relevantes es la referida insistencia del presente.

Cuando irrumpe la analepsis - claro cambio de la situación presente a otra pretérita-: «Cuando vino, mi casa cambió», aparecen otros recursos que presentifican la narración. El pasado se enuncia, por un lado, con verbos conjugados en presente: "Qué fuerzas tiene», «yo le hago burla», «ella se enoja de mentiras y también [me] remeda»; y por otro lado, a través de una proyección al futuro: «Ya no habrá piñatas, ni fiestas [...]. Ya se van a acabar las vacaciones». Este futuro está determinado por un hecho fundamental: «lo más sordamente triste es esto: mi prima, que vino unos días de visita, se vuelve mañana al rancho» (p. 57). Se percibe entonces un cambio abrupto: la analepsis no introduce el pasado, sino que se vuelve una añoranza proyectada hacia el futuro:

Ni quien la anime [a la casa] con tantos inventos de juegos bonitos y pláticas sabrosas: que allí viene la culebra y azota los cuamiles, que allí viene el coyote y se come las gallinas, que allí viene la lluvia y nacen las milpas, que allí viene el nahual y se pierden los niños... Ni jugaremos a los yunteros, a los sembradores, a los amansadores, a los piscadores... (p. 57; suspensivos del original; cursivas mías).

Puesto así, la memoria de Gabriel es «sordamente triste» no por lo que ocurrió, sino por lo que no ocurrirá. Su nostalgia - por definición, añoranza del pasado- es aquí una nostalgia del futuro.

Este rememorar en futuro es mucho más evidente en los planes del niño respecto de la prometida visita a su prima en el rancho, en tiempos de aguas: «caminaré entre las milpas, atravesaré los arroyos, treparé las barrancas» (p. 58); planes que, obviamente, incluyen jugar a las rondas: «Volveré a cantar», «les enseñaré mi espejito francés», «Con qué gusto y prontitud escogeré [a mi prima]» (p. 58), «ella

sitúa en el "exterior" de la diégesis que narra. El narrador extradiegético se coloca «casi siempre (pero no obligatoriamente) en una posición de ulterioridad» (Reis y Lopes, 1995, p. 175).

54. Díaz Roig, 1986, p. 45. 
sonreirá»; «Me tenderá las manos», «Yo me estremeceré sin saber por qué, imaginando muchas cosas» (p. 59). Estas acciones, que no han ocurrido y que quizá no ocurrirán, se enuncian en futuro pero están ancladas en la memoria.

De esta manera, el narrador mantiene la deixis en un presente preciso: la víspera de la partida de su prima; en un presente en el que tanto el pasado como el futuro están ocurriendo: ella «se vuelve mañana»-asevera-, es decir, ya se está yendo; «ni quien anime la casa», es decir, ella animó la casa. Sin embargo, otro rasgo de la presentificación quizá más interesante aún es precisamente que esa deixis es, también, dinámica. Tiene que ver con la simultaneidad de acciones, y también con la oralidad, incluso con cierta intención de escenificar el relato. Esto puede verse cuando, ansioso porque llegue el tiempo de aguas, Gabriel mueve las manecillas del reloj y es reprendido por su madre:

Quisiera ser dueño de los meses y darles vuelta tan aprisa como a las hojas de este calendario, como a las manecillas, siempre perezosas..

-Gabriel, vas a descomponer ese despertador, muchacho de porra [...]. Anda a la tienda a preguntar qué horas son (p. 59).

Aparentemente se trata de un diálogo ordinario, pero el cambio de deixis es poco convencional. El narrador nunca dice que ha movido las manecillas. Apenas las menciona, irrumpe la voz de la madre, reprendiéndolo, y sólo gracias a su regaño nos enteramos de lo que ha hecho el niño -mientras narraba. Si se tratase de un narrador extradiegético, la alternancia de voces no tendría nada de particular, entenderíamos que se ha cedido la voz a la madre. Pero aquí el narrador es autodiegético y narra mientras las acciones ocurren. Para establecer continuidad, debería usar introductores para luego citar la voz de la madre: «muevo las manecillas y mi madre me regaña». Pero no hay introductores y lo que haya ocurrido -no importa qué tan poco tiempo se haya tomado-, y que el narrador omite, afecta a la deixis.

El recurso, por lo demás, no es fortuito, sino que aparece de manera sistemática:

En el camino voy haciendo la cuenta: sesenta minutos - ¡cuántos!-, una hora; veinticuatro horas, un día; treinta...

- Las ocho y cuarto.

Las ocho y cuarto. Las ocho y cuarto, ya. Y no ha vuelto del centro, con mi tío, mi prima (p. 59).

Una vez más se omiten los introductores: «Llego a la tienda. Pregunto la hora. Me responden: "Las ocho y cuarto". Salgo de la tienda y vuelvo a la casa. Pienso: "no ha vuelto mi prima"...». Es sensato admitir que Gabriel habla mientras camina hacia la tienda, y luego de la tienda a su casa, modificando así el aquí y ahora. Esta ruptura deíctica imprime gran dinamismo a la narración.

Cuando llego a dar la hora, mi papá y mi mamá platican. Como no me advierten, me escondo tras de la puerta y oigo:

- Siempre se resolvió Cipriano a ponerla de interna y quiere que nadie sepa dónde (p. 59). 
Al enterarse de las intenciones de su prima, Gabriel exclama, entendemos que para sus adentros: «iYo podría pegarle al novio, desbaratarlo!» (p. 60); y luego establece la deixis final: «Son las ocho y cuarto de la noche. Y es día nueve de enero. Viernes. Nunca voy a olvidarlo. Tengo mucho frío. Me duele la cabeza» (p. 60).

No podemos menos que admitir la observación de Perus en el sentido de que en este relato el narrador enuncia a la manera de los narradores orales, como si lo hiciera ante un público espectador, y no ante un lector ${ }^{55}$. Esto es, la narración aparece entonces como una especie de performance ${ }^{56}$ : el aquí y ahora del narrador es móvil e instantáneo; apenas el narrador se mueve, la deixis cambia, como un narrador en escena.

El propio Agustín Yáñez nos ofrece la clave de esta composición en una entrevista con Emmanuel Carballo: «En ciertos episodios, Flor de juegos está pensado como un primer núcleo de un teatro de títeres, entretenimiento al que fui muy afecto en mi niñez» ${ }^{57}$. No sabemos si éste será uno de esos relatos pensados como guiñol, pero la referencia es reveladora.

El hecho de que el protagonista de «Episodio de las hebritas de oro» sea un niño, lógico de entrada, por cuanto las rondas son jugadas principalmente por los niños, en el relato se vuelve un asunto bastante significativo, sobre todo, en cuanto al aspecto de la presentificación que estamos revisando. Quiero decir que para un adulto la ronda constituye el recuerdo de un allá/en aquel tiempo, mientras que para un niño jugar la ronda es una ejecución, por tanto, una representación de la historia que cuenta. En el relato, Gabriel no recuerda la ronda y el episodio de su decepción amorosa desde su adultez, no cuenta un recuerdo, sino que narra lo que está ocurriendo aquí y ahora.

Aunque de manera un tanto marginal, no es ocioso recordar que, siendo uno de los primeros trabajos de Agustín Yáñez, Flor de juegos antiguos ofrece ciertas reminiscencias autobiográficas, nada menos que de su propia niñez. Observa Emmanuel Carballo: «no sólo es el primer libro importante de su bibliografía, sino también su primera aportación madura a las letras mexicanas»58; y en un texto bastante posterior, Carballo agrega:

55. Perus, 1993, pp. 327-368.

56. Además de la evidente acepción de «Actividad artística que tiene como principio básico la improvisación y el contacto directo con el espectador» (DRAE), es útil recordar la concepción de «realización» del acto lingüístico establecida por Chomsky, en oposición a la del dominio del lenguaje (Chomsky, 1966, pp. 9-10); y la de «acto de habla», por John L. Austin (1991). Sin embargo, con performance aludo aquí a la realización de un discurso en el momento en el que se producen las acciones que refiere. De entre la infinidad de definiciones, ayuda aquí la del teórico teatral Patrice Pavis: «El performer no debe ser un actor que interpreta un papel, sino sucesivamente un recitador, un pintor, un bailarín y, a causa de la insistencia puesta en su presencia física, un autobiógrafo escénico que establece una relación directa con los objetos y la situación de enunciación» (Pavis, 1998, p. 333). Ver San Cristóbal, 2018.

57. Carballo, 1994, p. 317.

58. Carballo, 1959. 
Sin Flor de juegos antiguos no se explica la obra posterior de Yáñez. Las líneas cortas y las líneas largas de su bibliografía parten de aquí. Este libro vale como fundación: en el transcurso de los años, soñarán los niños con conquistar el mundo - para ellos y para su progenitor ${ }^{59}$.

Por su parte, Gabriel Yáñez, hijo de Agustín Yáñez y homónimo del niño del cuento, refiere:

En las evocaciones de infancia de Flor de juegos antiguos, y en otros textos autobiográficos, en que se da a sí mismo el nombre de Mónico Delgadillo, nos cuenta indirectamente su niñez, adolescencia y juventud en Guadalajara, en donde - como él decía - se formó a impulso de sus campanas, de sus gentes. Casas de Guadalajara. Las del barrio del Santuario. Visión de un trenecito que corría por el viejo camino a Zapopan ${ }^{60}$.

Trejo Fuentes le llama al volumen de relatos «suerte de semblanza autobiográfica» $^{61}$. El propio Yáñez lo admite: «en este libro hay algunos rasgos de mi infancia» 62

No es casual que al escribir sobre su infancia Yáñez haya elegido las rondas que jugaba con sus vecinos, como una memoria de estos juegos y de sus mundos histórico e interior. Margit Frenk, en su Nuevo Corpus de la antigua lírica popular hispánica (siglos XV al XVII), advierte la relación entre la preservación del folklor y los niños citando a Demófilo: "Los niños han sido siempre más fieles al pasado y menos expuestos a las modas que los adultos» ${ }^{63}$; y a Pedro Cerrillo: "es el niño el emisor del testimonio folklórico» ${ }^{64}$. Frenk agrega que

existen muchas coincidencias entre esos testimonios y rimas infantiles de nuestro tiempo: como si los niños de hoy fueran los mismos -casi los mismosque vivieron en los siglos XVI y XVII (y aun podemos decir, como si fueran los mismos que vivieron en la Edad Media puesto que estas cancioncitas eran ya viejas cuando fueron recogidas). Como si los niños fueran inmunes a los cambios históricos, a la renovación de las corrientes culturales, al ir y venir de las modas poéticas ${ }^{65}$.

Tocamos aquí la relación, ya no sólo entre las rondas y la infancia, sino entre la infancia y la memoria misma. La recuperación de la infancia a partir de la reconstrucción de una ronda-romance presupone la configuración del pasado individual. Algo de la niñez hay siempre en la memoria, dice Bergson; el pasado «se conserva por sí mismo», «en todo instante nos sigue todo entero: lo que desde nuestra pri-

59. Carballo, 1997, p. 15

60. Yáñez, 1997, p. 26. Agustín Yáñez usaba el seudónimo de Mónico porque nació el día de Santa Mónica. Young, 1978, p. 25.

61. Trejo, 1997, p. 41.

62. Carballo, en Giacoman, 1973.

63. Demófilo, 1893, p. 159

64. Cerrillo, 2005, p. 467.

65. Frenk, 1973, p. 25 
mera infancia hemos sentido, pensado, querido, está ahí, inclinado sobre el presente con el que va a reunirse» ${ }^{66}$. Efectivamente, Flor de juegos antiguos «nos devuelve el sabor lejano de la infancia», asegura José Luis Martínez ${ }^{67}$. Y lo hace, además -tal es la tesis que he querido probar a lo largo de estas páginas-, a través de los mismos recursos por medio de los cuales el romance medieval, las rondas, la lírica infantil, han conseguido permanecer en la memoria de los niños. No es coincidencia que la percepción de la infancia se relacione con el juego y las rondas y que la percepción desde la adultez como un tesoro - «hebritas de oro»- sea clásica y antigua. Muestra suficiente es la «Canción de otoño en primavera» de Rubén Darío:

\author{
Juventud, divino tesoro, \\ iya te vas para no volver! \\ Cuando quiero llorar, no lloro... \\ $y$ a veces lloro $\sin$ querer ${ }^{68}$.
}

\title{
CONCLUSIONES
}

Perteneciente a los géneros romance y lírica infantil, la ronda «Hebritas de oro» porta las marcas esenciales: diálogo, rima, repetición, presentificación, que a su vez se replican en el relato de Yáñez. El soliloquio del niño protagonista y narrador, Gabriel, se produce en un presente que dinamiza la deixis; lo mismo que el diálogo del romance, no recuerda algo que pasó, sino que lo representa, pues enuncia las acciones en el momento en que ocurren. Incluso, el discurso de Gabriel, más que analéptico, es proléptico, en tanto que recuerda lo que no podrá ser en el futuro; narra los «recuerdos por venir» -en términos de Elena Garro. La ronda es el objeto de la añoranza, es la «paseidad», en términos de Ricoeur69, pero el niño coloca tal paseidad en el presente proyectándola hacia el futuro, donde no estará: «Ahora, mi casa volverá a ser como antes». Y aún es necesario observar cómo la memoria de la ronda resignifica el tiempo anterior, generando una segunda paseidad, la cual no se añora sino que se repudia: «mi casa volverá a ser como antes». El uso del subjuntivo - con su esquiva deixis - es aquí revelador: «Ni quien la anime con tantos inventos de juegos bonitos y pláticas sabrosas» (p. 57). La «paseidad», no la añorada, sino la repudiada, ahora volverá a ser ${ }^{70}$.

66. Bergson, 1997, pp. 47-48.

67. Martínez, 1949, p. 204.

68. Darío, 2007, p. 167

69. Afirma Ricoeur: «el referente último de la memoria sigue siendo el pasado, cualquiera que pueda ser la significación de la "paseidad" del pasado» (Ricoeur, 2004, p. 23).

70. Esto podría hacer mucho sentido con la afirmación de San Agustín sobre los tres tiempos: «Pero lo que ahora es claro y manifiesto es que no existen los pretéritos ni los futuros, ni se puede decir con propiedad que son tres los tiempos: pretérito, presente y futuro; sino que tal vez sería más propio decir que los tiempos son tres: presente de las cosas pasadas, presente de las cosas presentes, y presente de las futuras. Porque éstas son tres cosas que existen de algún modo en el alma, y fuera de ella yo no veo que existan: presente de cosas pasadas (la memoria), presente de cosas presentes (visión) y presente de cosas futuras (expectación)» (San Agustín, Las confesiones, pp. 485-486). 
¿No es este el papel del mito: añorar, no lo que ha sucedido, sino recordar lo que vendrá? ¿No es esta la función del romance? ¿No es esta la función de la ronda: rondar, jugar haciendo una 'rueda', 'retornar'?

Como es evidente, la mayoría de las correspondencias - o hilos - entre la ronda y el relato, están determinadas por un fenómeno que implícitamente hemos venido configurando: la citación. El relato de Yáñez está profundamente determinado por el discurso que cita: la ronda. Ésta, a su vez, supone una memoria telúrica y arcaica: la de la historia que cuenta el romance; la de los «juegos antiguos» ${ }^{71}$. La antigua elección amorosa por parte de un caballero quizá francés, relatada en diálogo; la presentificación de tal elección en la performance del juego.

Gabriel encarna la dimensión actancial del antiguo caballero al pretender a la prima «de trenzas de oro», aunque aquí se cancela la obtención del objeto de deseo. Como la ronda se relaciona con el antiguo romance, la voz de Gabriel se relaciona con la voz de los protagonistas de los otros relatos del libro -Agustín, Mónico-; y con la voz colectiva del «viejo Lucas Macías», en Al filo del agua, considerado por Francoise Perus «depositario de la memoria y socializador de la memoria colectiva» ${ }^{72}$.

No poca razón tiene Antonio Castro Leal cuando afirma:

En la vida del niño la poesía de esos juegos, los regocijos de las posadas, los desvelos de la misa de gallo, los días de asueto robados a la escuela, las batallas con los grupos rivales o las salidas al campo con la familia son como las únicas islas que se salvaron de un vasto territorio que se hundió en el olvido. Y en la memoria infantil sólo perduran los personajes que habitan esas islas encantadas ${ }^{73}$.

Autobiográfico y actualizador de la historia -o el mito- que la ronda conserva, el «Episodio de las hebritas de oro» - como los otros relatos de Flor de juegos antiguos - se estructura a partir de una memoria narrada en presente y proyectada al futuro. Autodiegético y mítico, el narrador imprime simultaneidad narrando en presente su memoria y su nostalgia por el porvenir. Las «hebritas de oro» tejen dos historias: la arcaica del romance y la íntima de Gabriel; y tejen también dos formas de narrar: el canto del romance vuelto ronda y el relato autodiegético. La actualización de la ronda es actancial y estructural; como en la ronda se juega más que se canta, Gabriel, más que narrar, escenifica.

\section{BiBLIOgRAFÍA}

Agustín, san, Las confesiones, traducción de Ángel Custodio Vega, Madrid, BAC, 1998.

Austin, John L., Cómo hacer cosas con palabras, Barcelona/Buenos Aires/México, Planeta, 1991.

71. «Los niños son muy viejos», dice Margit Frenk, al aludir a la permanencia de los juegos infantiles antiguos (Frenk, 1973).

72. Perus, 1993, p. 331

73. Castro Leal, «Prólogo», en Yáñez, 1963, p. vii. 
Bergson, Henry, Memoria y vida, textos escogidos por Gilles Deleuze, Madrid, Alianza, 1997.

Carballo, Emmanuel, «Flor de juegos antiguos, un mundo entre el ascetismo y la lujuria», en México en la cultura, suplemento cultural de Novedades, México, núm. 526, 12 de abril de 1959.

Carballo, Emmanuel, «Agustín Yáñez», en Helmy F. Giacoman (coordinador), Homenaje a Agustín Yáñez. Variaciones interpretativas en torno a su obra, Nueva York, Anaya-Las Américas, 1973, pp. 13-62.

Carballo, Emmanuel, Protagonistas de la literatura mexicana, México, Porrúa, 1994.

Carballo, Emmanuel, «Agustín Yáñez, novelista», Tierra adentro, 88, octubre-noviembre, 1997, pp. 12-24.

Castro Leal, «Prólogo», en Agustín Yáñez, Al filo del agua, México, Porrúa, 1963.

Cerrillo, Pedro, La voz de la memoria (Estudios sobre el cancionero popular infantil), Cuenca, Ediciones de la Universidad de Castilla-La Mancha, 2005.

Cerrillo, Pedro, «Presencia del Cancionero Popular Infantil en la literatura española de la Edad de Oro», Revista de Literatura, vol. LXXV, núm. 150, julio-diciembre, 2013, pp. 395-416.

Chomsky, Noam, Topics in the Theory of Generative Grammar, The Hague, Walter de Gruyter, 1966.

Darío, Rubén, Antología poética, introducción de Francisco Abad Nebot, Madrid, Edaf, 2007 [1ª ed., 1998].

Deyermond, A. D., Historia de la literatura española 1. La Edad Media, Barcelona, Ariel, 2001 [1ª ed., 1973].

Díaz Roig, Mercedes. Estudios y notas sobre el romancero, México, El Colegio de México, 1986.

Díaz Roig, Mercedes, «Introducción», en El Romancero viejo, México, Rei, 1987 [1984].

Garza Cuarón, Beatriz, «Claridad y complejidad en Muerte sin fin de José Gorostiza», en Revista Iberoamericana, 148-149, 1989, pp. 1129-1149.

Giacoman, Helmy F. (compilador), Homenaje a Agustín Yáñez. Variaciones interpretativas en torno a su obra, Madrid/New York, Anaya/Las Americas Publishing Company, 1973.

González, Aurelio, «La edición de un romancero mexicano», Abenámar, 1, 2016, pp. 215-222.

Frenk, Margit, «El folklore poético de los niños mexicanos», Artes de México, 62, 1973, pp. 5-30. 
Frenk, Margit, Nuevo Corpus de la antigua lírica popular hispánica (siglos XV a XVII), México, UNAM/El Colegio de México/FCE, 2003, 2 tomos.

Henríquez Ureña, Pedro, «Romances en América», en Pedro Henríquez Ureña y su aporte al folklore latinoamericano, ed. Eduardo Matos Moctezuma, México, El Colegio de México, 2008, pp. 53-76 [originalmente en Cuba Contemporánea, La Habana, noviembre-diciembre de 1913; La Lectura, Madrid, enero-febrero de 1914].

Henríquez Ureña, Pedro y Bertram D. Wolfe, «Romances tradicionales en México», en Pedro Henríquez Ureña y su aporte al folklore latinoamericano, ed. Eduardo Matos Moctezuma, México, El Colegio de México, 2008, pp. 23-49.

Lozano, Tomás, Cantemos al alba. Origins of Songs, Sounds and Liturgical Drama on Hispanic New Mexico, edición y traducción de Rima Montoya, prefacio de Anthony Cárdenas, Washington, Library of Congres Cataloging-in-Publication Data, 2007.

Martínez, José Luis, Literatura mexicana siglo XX, 1910-1949, I, México, Editorial Robredo, 1994.

Menéndez Pelayo, Marcelino, Antología de poetas líricos castellanos, tomo X, Madrid, CSIC, 1945.

Menéndez Pidal, Ramón, Los romances de América y otros estudios, Buenos Aires/ México, Espasa-Calpe Argentina, 1941.

Menéndez Pidal, Romancero hispánico (Hispano-portugués, americano y sefardí). Teoría e historia, Madrid, Espasa-Calpe, 1953, 2 tomos.

Milá y Fontanals, Manuel, De la poesía heroico popular castellana, Barcelona, Consejo Superior de Investigaciones Científicas, 1959.

Pavis, Patrice, Dictionary of Theatre. Terms, Concepts and Analysis, Toronto, University of Toronto Press, 1998.

Pelegrín, Ana, Cada quien atienda su juego, Madrid, Editorial Cincel, 1984.

Pelegrín, Ana, Juegos y poesía popular en la literatura infantil-juvenil, 1750-1987, tesis doctoral, Madrid, Universidad Complutense de Madrid, 2002.

Perus, Francoise, «La poética narrativa de Agustín Yáñez en Al filo del agua», en Agustín Yáñez, Al filo del agua, ed. crítica de Arturo Azuela, México, Conaculta (Colección Archivos, 22), 1993, pp. 327-368.

Reis, Carlos y Ana Cristina M. Lopes, Diccionario de narratología, Salamanca, Colegio de España, 1995.

Reyes, Alfonso, «Valor de la literatura hispanoamericana», en Obras Completas, tomo XI, México, FCE, 1960.

Ricoeur, Paul, La memoria, la historia, el olvido, Buenos Aires, FCE, 2004 [1. ${ }^{\text {a }}$ ed. en francés, 2000]. 
Rodríguez Marín, Francisco, «Varios juegos infantiles del siglo XVI», en Boletín de la Real Academia Española, 18, 1931, pp. 489-521 y 649-690.

Rulfo, Juan, Pedro Páramo, México, FCE, 1991.

San Cristóbal, Úrsula, «¿Acción, puesta en escena, evento o construcción audiovisual? Una breve introducción al concepto de performance en humanidades y en música», Cuadernos de música, artes visuales y artes escénicas, 13.1, enero-junio, 2018, pp. 207-231.

Trejo Fuentes, Ignacio, «Agustín Yáñez: mujeres enlutadas», Tierra adentro, 88, octubre-noviembre, 1997, pp. 40-47.

Yáñez, Agustín, «Cómo escribí La tierra prodiga», en La Cultura en México. Suplemento de Siempre! Disponible en <http://catalogoprofetica.ddns.net/opac-tmpl/ files/1962/Suplemento\%20no.\%201,\%20\%2021\%20de\%20febrero\%20de\%20 1962.pdf>.

Yáñez, Agustín, Al filo del agua, México, Porrúa, 1963.

Yáñez, Agustín, Flor de juegos antiguos, México, Organización Editorial Novaro, 1967.

Yáñez, Agustín, Al filo del agua, ed. crítica de Arturo Azuela, México, Conaculta (Colección Archivos, 22), 1993.

Yáñez, Gabriel, «Agustín Yáñez: una semblanza», Tierra adentro, 88, octubre-noviembre, 1997, pp. 25-28.

Young A., Richard, Agustín Yáñez y sus cuentos, Madrid/London, Tamesis Book Limited, 1978. 